\title{
Structural Study of the Activated Carbon Fiber using Laser Raman Spectroscopy
}

\author{
Jae-Seung Roh^ \\ School of Advanced Materials and System Engineering, Kumoh National Institute of Technology 1, Yangho-dong, Gumi, Gyungbuk 730-701, Korea \\ •e-mail:jsroh@kumoh.ac.kr \\ (Received May 2, 2008; Accepted June 5, 2008)
}

\begin{abstract}
This study aims to find a correlation between XRD and Raman result of the activated carbon fibers as a function of its activation degrees. La of the isotropic carbon fiber prepared by oxidation in carbon dioxide gas have been observed using laser Raman spectroscopy. The basic structural parameters of the fibers were evaluated by XRD as well, and compared with Raman result. The La of the carbon fibers were measured to be $25.5 \AA$ from Raman analysis and $23.6 \AA$ from XRD analysis. La of the ACFs were $23.6 \AA$ and $20.4 \AA$, respectively, representing less ordered through activation process. It seems that the $\mathrm{I}_{\mathrm{D}} / \mathrm{I}_{\mathrm{G}}$ of Raman spectra were related to crystallite size(La). Raman spectroscopy has demonstrated its unique ability to detect structural changes during the activation of the fibers. There was good correlation between the La value obtained from Raman and XRD.
\end{abstract}

Keywords : Raman, XRD, La, Crystallinity, Activation

\section{Introduction}

Microporosity of activated carbon fibers (ACFs) was recognized to be influenced by the crystallite structures of the porous materials [1-4]. The crystallite structure is characterized with the interlayer spacing $\left(\mathrm{d}_{002}\right)$, crystallite thickness (Lc), crystallite width (La), the relative degree of crystallinity (Dc) and the number of aromatic layer (Ns). The interlayer spacing $\left(\mathrm{d}_{002}\right)$ of disordered carbon materials would be in range of $3.4 \sim 8 \AA$, which is usually much larger than that of graphite [5-9]. In early study the specific surface area (SSA) variations were investigated on the basis of the pore structures characterized by the structural analysis and activation kinetics for the ACFs [10-11].

Most of researchers tried to interpret structural parameters of carbon materials via several analyzing techniques such as XRay diffraction (XRD), High Resolution Transmission Electron Microscopy (HRTEM) and Raman spectroscopy [12-14].

Raman spectroscopy has been a major experimental technique to determine information about the microstructure of various carbon materials. Tuinstra and Koenig first reported that an relationship between the crystallite size La obtained from XRD and the intensity ratio of the two major Raman bands in disordered non-graphitic carbons [15-16]. Since numerable studies on carbons using Raman spectroscopy were reported that the Raman spectroscopy has been become commercial method to determine the structural study of carbon based materials [17-19]. Highly ordered graphite shows only one band in the region of 1100 and
$1700 \mathrm{~cm}^{-1}$ and shows second order features between 2400 and $3300 \mathrm{~cm}^{-1}$. The Raman spectra change significantly for disordered carbons and show D band at around $1350 \mathrm{~cm}^{-1}$. Therefore the characteristic Raman spectra for synthetic graphite show peaks at around $1350 \mathrm{~cm}^{-1}$ for disordered carbon (D band) and $1580 \mathrm{~cm}^{-1}$ for graphitized carbon (G band). The degree of graphitization may be estimated by examining the Raman spectra for a specimen. Relative intensity between $\mathrm{G}$ band and $\mathrm{D}$ band changed by heat treatments, crystallite size of the disordered carbon, and crystallinity.

In this study structural changes of isotropic carbon fibers prepared by oxidation in carbon dioxide gas have been observed using laser Raman spectroscopy. The basic structural parameters of the fibers were evaluated by XRD as well, and compared with Raman result. Also the specific surface area (SSA) variations were measured on the basis of the pore structures characterized by the structural analysis for the ACFs.

\section{Experimental Procedures}

\subsection{Sample preparations, $B E T$ and $X R D$ analysis}

A pitch-based carbon fiber was used as a base material. They were isotropic carbon fibers carbonized below $1,000^{\circ} \mathrm{C}$. The physical properties of the fibers, activation conditions, and the result of XRD spectra were early 


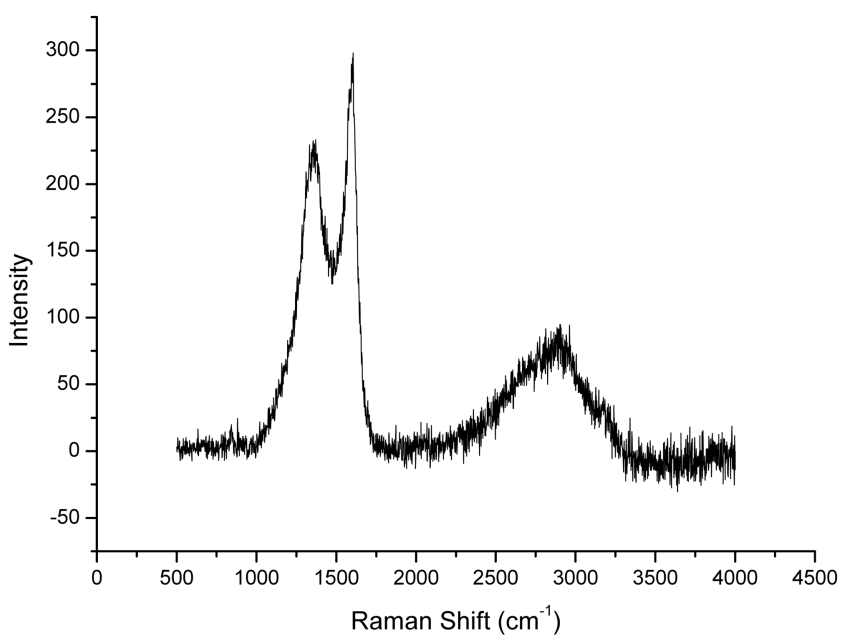

Fig. 1. Raman spectrum of the original carbon fiber.

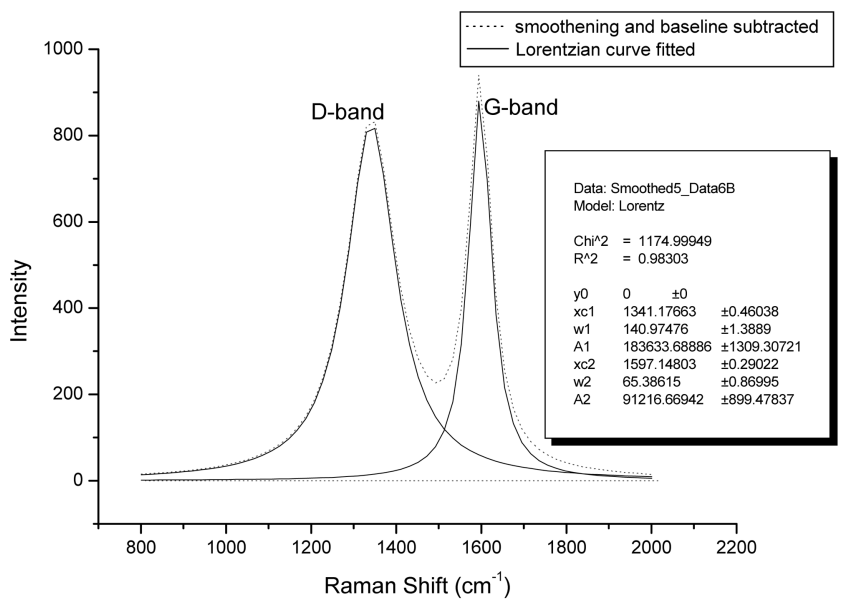

Fig. 2. Result of Lorentzian curve-fitting of the first-order D and $\mathrm{G}$ band.

reported [10]. The SSA was gained from adsorption isotherms on the basis of the BET equation, and micropore volume $\left(\mathrm{V}_{\mathrm{P}}\right)$ and external surface area $\left(\mathrm{S}_{\mathrm{EX}}\right)$ were obtained by t-plot. The Lc and La values were calculated by the Scherrer equation.

\subsection{Raman Analysis}

For the Raman analysis, $\mathrm{a} \times 500$ magnification microscope is used to select a point to focus laser beam spot on the fiber surface. The wavelength and laser beam size of the facility were $514.5 \mathrm{~nm}$ of argon laser (Green) and $\sim 2 \mu \mathrm{m}$ of diameter.

Extended scans from 500 to $4000 \mathrm{~cm}^{-1}$ were performed to obtain both the first- and second-order Raman bands of the carbon fibers. Static scans were also obtained in order to enhance the signal that was subsequently analysed. Typical exposure times for carbon fibers ranged from 10 to $20 \mathrm{~s}$ for the scans. The band intensity, band width and band position were obtained from static scans of the first-order Raman spectra using a Lorentzian curve-fitting procedure. Fig. 1 and Fig. 2 show scan result of original fiber and result of Lorentzian curve-fitting, respectively.

\section{Results and Discussion}

\subsection{Pore structure}

The pore structures of the ACFs were summarized in Table 1 [10]. In general specific surface area (SSA), external surface area $\left(\mathrm{S}_{\mathrm{EX}}\right)$, width of pore $\left(\mathrm{W}_{\mathrm{P}}\right)$ and pore volume $\left(\mathrm{V}_{\mathrm{P}}\right)$ of the ACFs were increased with increasing burn-offs. These results propose that high specific surface area could be developed from micropores. The ACFs with burn-off 59\% activated at $900^{\circ} \mathrm{C}$ showed the maximum SSA of $3,495 \mathrm{~m}^{2} / \mathrm{g}$ from average $\mathrm{W}_{\mathrm{P}}$ of $8.3 \AA$.

\subsection{XRD analysis}

The structural parameters gained from diffraction peaks were summarized in Table 2. The Lc and La values of the original fibers were $6.2 \AA$ and $23.6 \AA$. The interlayer spacing of the original fiber was relatively large as $4.04 \AA$ in comparison with $3.35 \AA$ than that of graphite. With increasing burn-offs, the interlayer spacing increased up to $4.76 \AA$ and Lc increased up to $6.7 \AA$. So the increasing of Lc caused merely widening of interlayer spacing.

On the contrary, it was considered that the decreasing of La as the burn-offs increased was caused by removal of carbon atoms at the edge of crystallites. Therefore, it was cleared that the crystallinity of activated fibers became more disordered and the size of crystallites of ACFs became smaller than original fibers.

\subsection{Raman analysis}

Fig. 3 shows only the first-order Raman spectra as a func-

Table 1. Specific Surface Area (SSA), External Surface Area $\left(S_{E X}\right)$, Micropore Volume $\left(V_{P}\right)$, and Pore $W_{i d t h}\left(W_{P}=2 V_{P} / S S A\right)$ of ACFs.

\begin{tabular}{cccccc}
\hline Temperature $\left({ }^{\circ} \mathrm{C}\right)$ & Burn-off $(\%)$ & $\mathrm{SSA}\left(\mathrm{m}^{2} / \mathrm{g}\right)$ & $\mathrm{S}_{\mathrm{ex}}\left(\mathrm{m}^{2} / \mathrm{g}\right)$ & $\mathrm{V}_{\mathrm{P}}(\mathrm{cc} / \mathrm{g})$ & $\mathrm{W}_{\mathrm{P}}(\AA)$ \\
\hline \multirow{2}{*}{900} & 39 & 1156.1 & 28.7 & 0.4622 & 8.0 \\
& 59 & 3494.8 & 178.7 & 1.4590 & 8.3 \\
& 79 & 3104.5 & 141.3 & 1.4582 & 9.4 \\
\hline
\end{tabular}


Table 2. Structural Parameters of the Isotropic Carbon Fibers Obtained from XRD.

\begin{tabular}{ccccc}
\hline $\begin{array}{c}\text { Burn-off } \\
(\%)\end{array}$ & $\begin{array}{c}\mathrm{d}_{002} \\
(\AA)\end{array}$ & $\begin{array}{c}\mathrm{d}_{10 l} \\
(\AA)\end{array}$ & $\begin{array}{c}\mathrm{Lc} \\
(\AA)\end{array}$ & $\begin{array}{c}\mathrm{La} \\
(\AA)\end{array}$ \\
\hline Original fiber & 4.04 & 2.10 & 6.2 & 23.6 \\
59 & 4.29 & 2.12 & 6.4 & 22.7 \\
79 & 4.76 & 2.10 & 6.7 & 20.4 \\
\hline
\end{tabular}

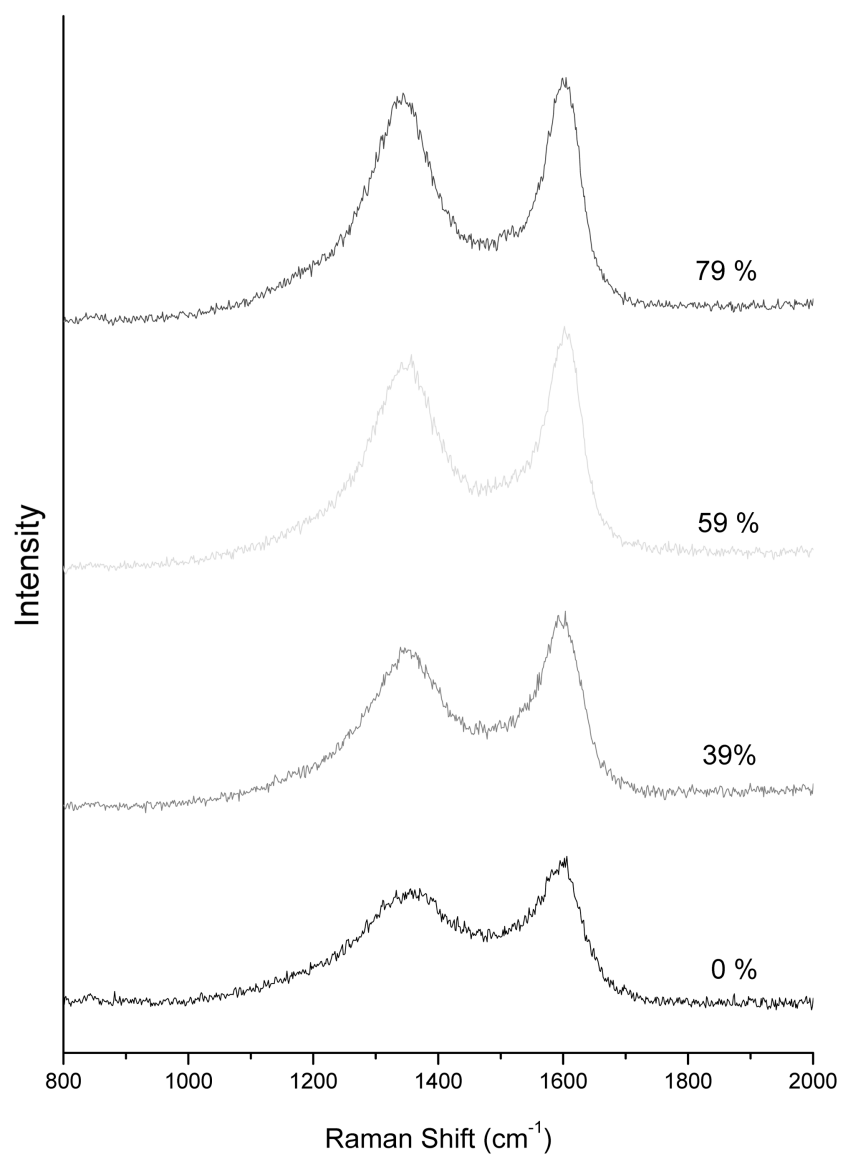

Fig. 3. The first-order $D$ and $G$ band changes as a function of burn-off degrees.

tion of burn-off degrees of the carbon fibers studied in this work. In all cases the spectra exhibited the same appearance, that is, two well-resolved bands, namely $\mathrm{D}\left(\sim 1330 \mathrm{~cm}^{-1}\right)$ and $\mathrm{G}\left(\sim 1580 \mathrm{~cm}^{-1}\right)$ band.

In Fig. 4 the activation process affect the position of the Raman bands. There were no significant differences exist between the positions of the $\mathrm{G}$ bands. However the $\mathrm{D}$ band

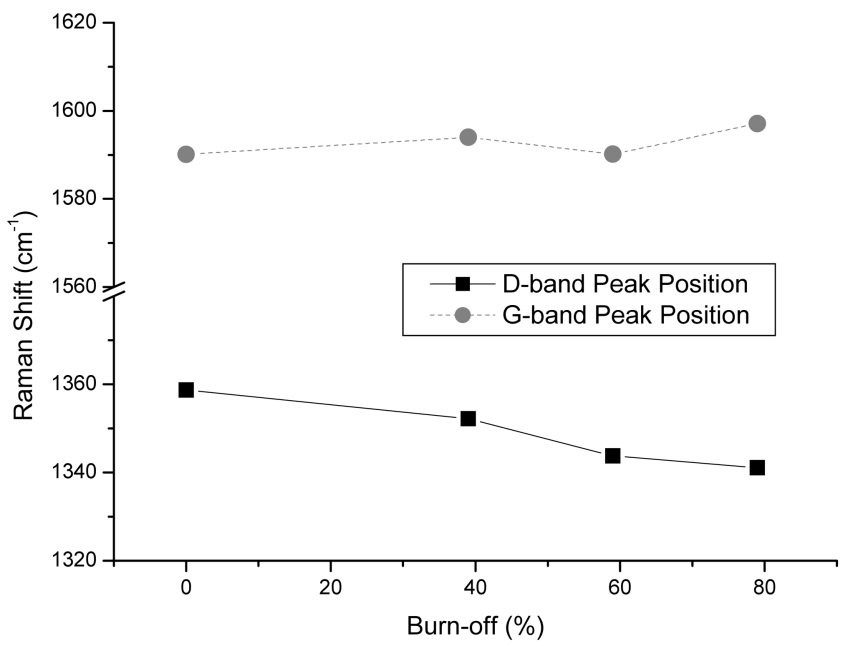

Fig. 4. Peak position changes of the first-order D and G band.

positions were slightly changed. The position of the $\mathrm{D}$ band seems to shift to lowerer wavenumber as the burn-offs increases. This is possibly due to the poorly organization of carbon materials (i.e., more disorder) $[16,20]$.

The intensity ratio $\left(\mathrm{R}=\mathrm{I}_{\mathrm{D}} / \mathrm{I}_{\mathrm{G}}\right)$ of the two first-order bands $\mathrm{D}$ and $\mathrm{G}$ is always higher a as function of burn-offs. To quantify and corroborate this observation, the intensities of the bands in the first-order region of the Raman spectrum (D and $\mathrm{G}$ ) are given in Table 3. Although this is a common consequence for the activated fibers, it is clear that the intensity ratio rapidly increase over 39\% burn-off. These rapid changes of band intensities must be discussed in terms of differences in the structure of the fibers. Lespade and other researchers showed the intensity ratio $\left(\mathrm{R}=\mathrm{I}_{\mathrm{D}} / \mathrm{I}_{\mathrm{G}}\right)$ of the two first-order bands $\mathrm{D}$ and $\mathrm{G}$ is related to the structure of carbon materials [21,22].

As mentioned in early report, it was obvious that each layer consisting of fibers became more disordered as the burn-off proceeded, and the layer stacking became imperfect [10]. The structural parameters gained from XRD diffraction peaks were summarized in Table 2. The Lc and La values of the original fibers were $6.2 \AA$ and $23.6 \AA$, representing stacks of less than two layer planes. The structure proposes that the layers are randomly distributed to be random active sites. The interlayer spacing of the original fiber was relatively large as $4.04 \AA$ in comparison with $3.35 \AA$ than that of graphite. With increasing burn-off, the interlayer spacing increased up to $4.76 \AA$ and Lc increased up to $6.7 \AA$.

Table 3. Peak Position, Peak Intensity, and $\mathrm{R}\left(=\mathrm{I}_{\mathrm{D}} / \mathrm{I}_{\mathrm{G}}\right)$ Values of the First-order $\mathrm{D}$ and $\mathrm{G}$ band.

\begin{tabular}{|c|c|c|c|c|c|}
\hline \multirow{2}{*}{$\begin{array}{c}\text { Burn-off } \\
(\%)\end{array}$} & \multicolumn{2}{|c|}{ Peak Position } & \multicolumn{2}{|c|}{ Peak Intensity } & \multirow{2}{*}{$\begin{array}{c}\mathrm{R} \\
\left(=\mathrm{I}_{\mathrm{D}} / \mathrm{I}_{\mathrm{G}}\right)\end{array}$} \\
\hline & D-band & G-band & D-band & G-band & \\
\hline 0 & 1358.7 & 1590.1 & 216.7 & 251.5 & 0.8616 \\
\hline 39 & 1352.2 & 1594.0 & 234.8 & 270.9 & 0.8667 \\
\hline 59 & 1343.8 & 1590.2 & 659.7 & 721.6 & 0.9142 \\
\hline 79 & 1341.1 & 1597.1 & 829.3 & 888.1 & 0.9338 \\
\hline
\end{tabular}


Table 4. La values obtained from Raman and XRD.

\begin{tabular}{ccc}
\hline \multirow{2}{*}{$\begin{array}{c}\text { Burn-off } \\
(\%)\end{array}$} & \multicolumn{2}{c}{$\mathrm{La}(\AA)$} \\
\cline { 2 - 3 } & $\begin{array}{c}\text { Raman result } \\
(\mathrm{La}=\mathrm{C} / \mathrm{R}, \mathrm{C}=20)\end{array}$ & $\begin{array}{c}\text { XRD result } \\
\text { (by Scherrer eq. })\end{array}$ \\
\hline 0 & 23.2 & 23.6 \\
39 & 23.1 & - \\
59 & 21.9 & 22.7 \\
79 & 21.4 & 20.4 \\
\hline
\end{tabular}

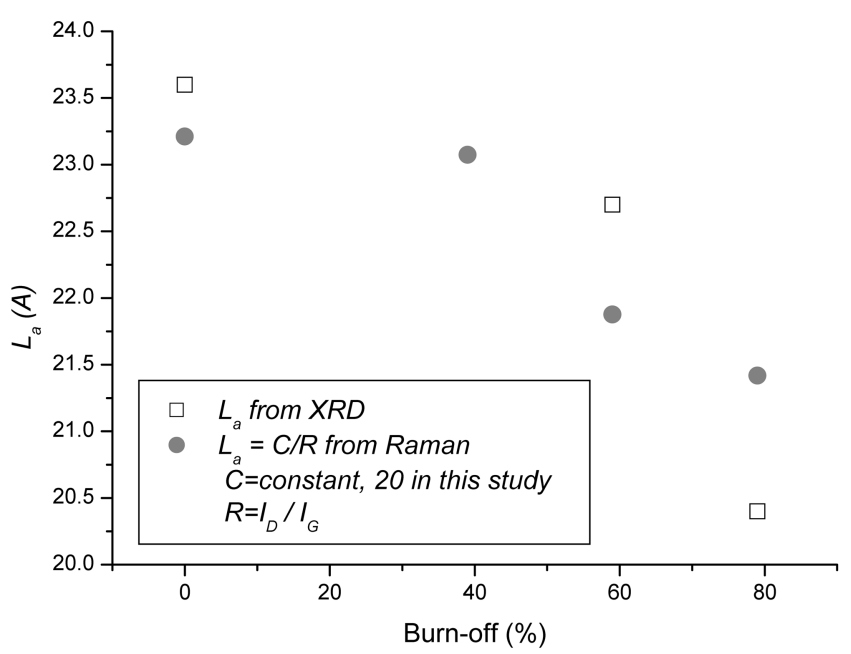

Fig. 5. Correlation of La values between Raman and XRD result.

So, the increasing of Lc caused merely widening of interlayer spacing.

From the Raman and the XRD result, it was considered that the decreasing of La as the burn-off increased, was caused by removal of carbon atoms at the edge of crystallites. Therefore, it was cleared that the crystallinity of activated fibers became more disordered and the size of crystallites of ACFs became smaller than original fibers.

The rapid increasing of the Raman band intensity ratio with over $39 \%$ related to the rapid increasing of the SSA that the burn-offs was over $39 \%$. The SSA of $59 \%$ burn-offed activated fiber was $3,495 \mathrm{~m}^{2} / \mathrm{g}$ that compared to the $1,156 \mathrm{~m}^{2} / \mathrm{g}$ of $39 \%$ burn-offed fiber.

The structural parameter La of the fibers obtained from Raman compares well also with the structural parameters obtained from X-ray diffraction in Table 4 and Fig. 5. The La values from Raman analysis was calculated by using $L_{a}=C / R$, here $R=I_{D} / I_{G}$ and constant $C$ was 20 in this study. It seems clear from Fig. 5 there was good correlation between the La value obtained from Raman and XRD.

\section{Conclusions}

Structural changes of isotropic carbon fibers prepared by oxidation in carbon dioxide gas have been observed using laser Raman spectroscopy. The basic structural parameters of the fibers were evaluated by XRD as well, and compared with Raman results.

Raman spectra of the treated fibers have shown a considerable increase of the intensity ratio of the two firstorder bands D and G. This has been interpreted as an increase of the fiber structural disorder, possibly through the presence of a higher proportion of edge planes in the surface of the treated fibers. Therefore, it was cleared that the crystallinity of activated fibers became more disordered and the ACFs show high SSA.

Raman spectroscopy has demonstrated its unique ability to detect structural changes during the activation of the fibers. There was good correlation between the La value obtained from Raman and XRD.

\section{References}

[1] Lu, S.; Blanco, C.; Rand, B. Carbon 2000, 38, 3.

[2] Sharma, A.; Kyotani, T.; Tomita, A. Carbon 2000, 38, 1977.

[3] Kercher, A. K.; Nagle, D. C. Carbon 2003, 41, 15.

[4] Yoshzawa, N.; Maruyama, K.; Yamada, Y.; Zielinska-Blajet, M. Fuel 2000, 79, 1461.

[5] Oberlin, A.; Villey, M.; Combaz, A. Carbon 1980, 18, 347.

[6] Warren, B. E. The Physical Review 1941, 59, 693.

[7] Yen, T. F.; Erdman, J. G.; Pollack, S. S. Analytical Chemistry 1961, 33, 1587.

[8] Ludwig Schoening, F. R. Fuel 1983, 62, 1315.

[9] Shim, H. S.; Hurt, R. Carbon 97 July 18-23, 1997, 438.

[10] Roh, J. S.; Suhr, D. S. Carbon Science 2004, 5, 51

[11] Roh, J. S. Carbon Science 2005, 6, 1

[12] Carrot, P. J. M.; Sing, K. S. W., "Characterization of Porous Solid”, ed. Unger, K. K.; Rouquerol, J.; Sing, K. S. W.; Kral, H., Elsevier Sci. Publ., Amsterdam, 1988, 77.

[13] Mittelmeijer-Hazeleger, M. C.; Martin-Martinez, J. M. Carbon 1992, 30, 695.

[14] Marsh, H. Carbon 1987, 25, 49.

[15] Ferrari, A. C. Solid State Communications 2007, 143, 47.

[16] Montes-Moran, M. A.; Young. R. J. Carbon 2002, 40, 845.

[17] Hardwick, L. J.; Novak, P.; Buqa, H. Solid State Ionics. 2006, 177, 2801.

[18] Hirai, T,; Compan, J.; Niwase, K.; Linke, J. Journal of Nuclear Materials 2008, 373, 119.

[19] Perraki, M.; Proyer, A.; Mposkos, E.; Kaindl, R.; Hoinkes, G. Earth and Planetary Science Letters 2006, 241, 672.

[20] Kuo, C. T.; Wu, J. Y.; Lu, T. R. Materials Chemistry and Physics 2001, 72, 251.

[21] Lespade, P.; Al-Jishi, R.; Dresselhaus, M. S. Carbon 1982, 20, 427.

[22] Escribano, R.; Sloan, J. J.; Siddique, N.; Sze, N.; Dudev, T. Vibrational Spectroscopy 2001, 26, 179. 